\title{
A Professional Ethics for Researchers?
}

\author{
Nathan Emmerich
}

\section{Contents}

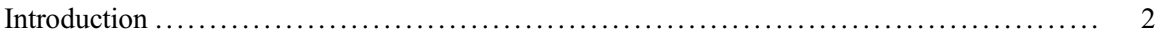

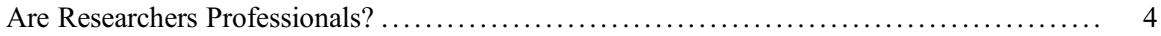

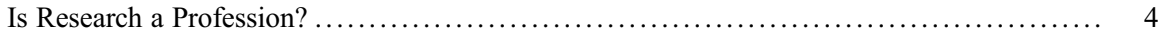

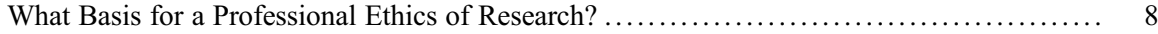

Rethinking Research Ethics as a Professional Ethics .............................. 12

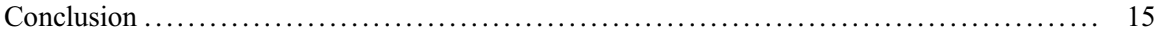

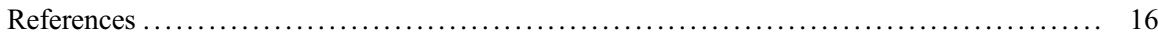

\begin{abstract}
Historical research has shown that, at its inception, research ethics was conceived as distinct from existing discourses of professional ethics. Subsequently, this distinction has been maintained and, as a result, the discourse of research ethics appears to be an external to and independent of the practices it normatively analyses and comments upon. This chapter challenges these founding preconceptions and considers if research ethics can be understood as a professional ethics. Therefore, this chapter examines the criteria sociological research identifies as constitutive of a profession, and while one might conclude that research is obviously not formally instantiated as a profession, some of the sociological criteria have significant relevance. In this light it is argued that we might rethink the notion of research ethics in terms of a professional ethics. To do so would be to more clearly embed ethical discourse in the practice(s) of research, something that is consistent with the current turn to integrity.
\end{abstract}

N. Emmerich $(\bowtie)$

Australian National University, Canberra, Australia

e-mail: nathan.emmerich@anu.edu.au 


\section{Keywords}

Research ethics · Professional ethics · Professions · Professionalization - Social institutionalization $\cdot$ Social organization

\section{Introduction}

In a previous essay, I have argued against the seemingly common, if more or less implicit, understanding of research ethics and professionals ethics as distinct from one another in some reasonably strong sense (Emmerich 2016b). As the accounts of the historical emergence of research ethics offered by Schrag (2010) and Stark (2011) show, the idea of a research ethics emerged at a particular time and place - the National Institutes of Health (NIH) in Bethesda Maryland, USA, circa the 1950s. At least in part, the notion of a research ethics was designed to circumnavigate the multiple and potentially conflicting professional ethics of those working in this context. It was also conceived so as to address a new class of patient - the normal or healthy patient - on whom researchers were increasingly reliant. As such individuals were not undergoing any treatment, they could not be seen as entering into a doctor-patient relationship. This was understood to call into question the healthcare professional's fiduciary duties, and, particularly when understood in the aftermath of unethical research by medical doctors during World War II, this was taken to mean that the norms of professional medical ethics could not be relied upon as the basis for protecting such patients.

Tracing the roots of research ethics to the complex challenges faced by researchers and those managing them at this time in the NIH can be taken in a number of ways. One might think that while research, particularly biomedical research, is undertaken by those commonly thought of as professionals, it is distinct from their constitutive professional practices. Therefore, both the practice of research and its associated ethics are rightly conceived of as distinct from the discourse on professional ethics and a concern external to the profession of medicine as a whole. (Of course one does not mean to imply that an internal discourse on professional ethics is or can be fully autonomous or entirely uninfluenced by external factors. This is not the case, and it is right that the discourses surrounding medical ethics and research ethics are open to external inputs. The question is, however, where we consider the locus of debate to be.) However one might alternatively think that researchers either were, or subsequently became, a de facto class of medical professionals. Consider, for example, medical and healthcare professionals who specialize in biomedical research, who pursue a career in research and in locations where such work commonly takes place. In this context while research ethics, including its associated administrative bureaucracy, was initially aimed at preempting potential conflicts between existing specialisms and their associated professional ethics, it might now be taken as reflecting the ethics of this new professional class. As such it can be understood as moral discourse that is internal to a particular practice or professional pursuit. 
This distinction may or may not have significance for the way in which (biomedical) research is pursued, how the ethics of research is understood, and, perhaps more significantly, its implementation, administration, and governance. However, the difference between these two perspectives might be thought of as taking on additional significance when it comes to thinking though the ethics of social research. For the most part, social researchers are researchers first and foremost. Thus, the ethics of social research is not required to preemptively mollify conflicts between allegiances to preexisting codes of professional ethics. Indeed, there is no reason to think of the activity of research as being in conflict with the responsibilities of some other (professional) practice. Quite evidently there are examples where this might not be the case. Where a management researcher is engaged in a reflexive action research project, say, or when a psychologist or a linguist undertakes research with their clients. However, the point here is to address the ethics of research qua the professional researcher and, on that basis, to reimagine the way we think about research ethics. It is, then, worth more fully thinking through the idea of an ethics of research in terms of a professional ethics, or so one might think. What follows can be considered an attempt to do so, albeit in admittedly broad terms. Presuming that this account is convincing or, at least, provides the reader with further food for thought, then the other chapters presented in this section can be viewed as doing the heavy lifting; the more detailed work required when it comes to the more substantive ethical issues encountered by professional researchers working within particular disciplines or utilizing specific methodologies when undertaking research.

This chapter proceeds as follows. First the suggestion that researchers are professionals is considered before turning to the more substantive question of whether research is a profession. While it is clear that research is not institutionalized in a manner that reflects the true or classic professions of medicine or law, it is argued that there is some reason to construe research as a professional activity. In light of this conclusion, the basis for a professional ethics of research is then examined, namely, whether or not one can think that an (implicit) social contract obtains between researchers and the societies within which they pursue their activities.

One final point or set of related points is worth making here. For the most part, this chapter is concerned with academics, those who pursue their research within universities. However, just as there are medical professionals who practice medicine privately or who are employed by private corporations other than hospitals or similar institutions, there are researchers who are not employed by universities, and who pursue their work independently, or who work for particular nonacademic organizations. In this context, one might think that pursuing research ethics as a professional ethics more clearly includes such individuals than is the case with research ethics, particularly since the administration of research ethics tends to be associated with institutions dedicated to the pursuit of academic research. Nevertheless, questions remain, and it may well be that the professional ethics of researchers should be understood as sensitive to the context of practice. This is something that applies to other professional practices; the ethical responsibilities that attend patient care differ from those that attend healthcare professionals 
working for, say, insurance companies or state bodies such as those that administer state benefits. As such, situational variation presents at least as much of a challenge to the discourse of research ethics as it does to the notion of a professional ethics of research.

\section{Are Researchers Professionals?}

The notion that the ethics of research should be understood as a professional ethics presumes that conducting research entails being a professional. The question of whether or not researchers are professionals can be defended with relative ease, but it turns out to be the wrong question or, at least, an incorrect place to start an enquiry into the viability of a professional ethics for research. Nevertheless, consider the fact that a great number of the activities that are undertaken in contemporary society can be thought of as being done in a manner that is more or less professional or with greater or less degrees of professionalism. Given the present meaning of the term "professional," it makes sense to say that a plumber or some builders acted in a professional or unprofessional manner or that they acted with professionalism. Here being professional - as opposed to being a professional - does not require one to be a member of a profession. Rather, the notion is coterminous with certain contemporary behavioral standards, norms, or expectations that are related to those acting within the marketplace or the public sphere. Such standards reflect an ethic or an ethos that, at least to some degree, involves the suspension of certain personal, cultural, and political norms and the adoption of the kind of tolerant or nonjudgmental standpoint that might be termed cosmopolitan.

While it is significant that normative concerns are central to contemporary idea of being professional, or acting with professionalism, this does not mean it is tantamount to a (supra)professional ethics. Nevertheless, it is something that can be applied to researchers. Whether or not they are interacting with academic or administrative colleagues, or with research participants, one can and should expect researchers to act professionally. Nevertheless, affirming that researchers should be professional when conducting research does not get us very far with the matter at hand; it concerns broad standards of behavior applicable to a wide range of persons engaged in a wide range of (largely public) activities. The notion of a professional ethics of research is a more specific idea, and one tied to the practice of research and of being a professional, in the sense of being a member of a profession. Thus, the relevant question is whether or not research can be thought of as constituting a profession.

\section{Is Research a Profession?}

On the face of it, it would seem that research cannot be thought of as a profession. While some argue that research is research, to my mind this is not the case. Following Schrag (2014), one might think that research - or, even, human subjects 
research which, after all, is what we are primarily concerned with when it comes to research ethics - contains a multitude. It is diverse and should not be reduced to a singular activity or practice; it is not any one thing. As such, one cannot simply maintain that researchers are all members of the same profession on the basis that there are all engaged in the same basic task. Nevertheless, rather than abandon the notion entirely, it is worth pursuing the idea a little further.

In what follows, the focus on what might be called the formal account of professionalization, i.e., one that is focused on the social and historical processes that created the formal or classical professions, such as medicine and law, and which began in the eighteenth century. This can be contrasted with the informal or cultural account, which offers insight into the broader twentieth-century processes that foreground the notion of professionalism noted in the previous section (cf. Evetts 2003, 2013). The reasons for doing so are multiple. First, academic institutions predate the formal professions and, arguably, influenced their development, not least insofar as the term professor and profession are related to one another. Second, the centrality of ethics and the need for it to be given a distinct expression, primarily in a codified form, in accounts of the creation of formal professions are of particular significance to the arguments made here. Third, while it seems clear that informal processes of professionalization have had an effect on academic institutions and research, if one were to attend to this, then it would unavoidably lead to a focus on developments in the management and administration of such organizations: the professionalization of the managerial class as opposed to the class of "coal face" academic, even if they have also been affected by these developments. In turn, this would result in a critique of research ethics as a bureaucratic behemoth; an administrative and managerial enterprise, masquerading as something else, particularly in the context of social research. Aspects of this point have been and continue to be well made elsewhere (cf. Hedgecoe 2016). The purpose at hand is to try and reclaim research ethics as something that can be reoriented so as to make a more positive contribution to the practice(s) of (social) research and researchers. The formal account of professionalization and the notion of professional ethics as a collective rather than managerial enterprise offer the best opportunity to advance this agenda.

For there to be a profession in the formal sense of the term, what is required is the identification of a (set of) practice(s) such that a coherent occupational group can or perhaps needs - to be formalized or institutionalized in a sociopolitical sense. Thus, the (historically) "ideal professions" of medicine and law involved a certain set of practices, the standards for which are set and ensured by the relevant professional bodies. These practices also provide or support central social goods; they enable the health of citizens and the rule of law, a prerequisite of the modern democratic societies and nation states. It is also worth noting that the process of becoming a professional - of joining these professional bodies - involves individuals undertaking (extensive) educational programs that provide the relevant credentials, followed by a period of "on-the-job" training that one might consider as a kind of apprenticeship. Such processes can be perceived in a number of modern occupational groups including nursing, accountancy, architecture, and teaching. Indeed, one might also apply such thinking to the police, the military, 
and the clergy - the latter two also being occupations that were historically considered to be professions.

It is in this context that one might consider whether or not researchers are professionals in the relevant sense. Although research is not institutionalized in any singular form, it would be glib to say that research is not a profession on this basis alone. In the first instance, just as there are various kinds of researcher whose practices differ from one another - those who work within the natural sciences, the social sciences, and the humanities, for example - one might compare these to the different specialties that constitute the medical profession as a whole. Indeed, one might draw attention to the differences between various healthcare professionals and note that where we draw the boundaries of a profession and the line between one profession and another are not timeless metaphysical truths but function of the socio-historical developments that produced them. Similar points can be made about the practice of research and researchers, particularly with regard the emergence of disciplinarity (Wellmon 2015) or, to put it another way, specialization. The social institution of the university emerged prior to the development of disciplinarity, something that continues to be reflected by the fact that the terminal degree of almost all fields and institutions is the $\mathrm{PhD}$ - the Doctorate in Philosophy. Thus, while scholars who work in particular fields of disciplines have forged connections with those in other institutions, including through the formation of societies and associations - examples of which range from historically significant national bodies such as the Royal Society, the Royal Society of Chemistry, the British Academy, and the American Academy of Arts and Sciences, to well-established and influential organizations such as the British Sociological Association, and to smaller groups of significance to particular fields, such as the Socio-Legal Studies Association and so forth - the fact that researchers had a preexisting and stable home or employer has meant the absence of any sociopolitical need for formal recognition, i.e., the formal establishment or institutionalization of research disciplines as professions.

Thus, while disciplinarity emerged around the same time as medicine underwent a formal process of professionalization, beginning in the late eighteenth and continuing through most of the nineteenth century, this was predated by the university as a sociopolitical institution. Indeed, the idea of an academic, scholar or professor, i.e., someone who professes their knowledge, predates the subsequent emergence of the professional. Thus one might take the view that although academics have never been (explicitly) perceived as members of a profession, some facet of the notion has always been present within the culture of academia and the role that they play in society. Furthermore, the development of disciplinarity, specialization, and the processes through which they have become institutionalized within the universities and across the practices of knowledge production arguable reflects conceptions of professionalization as a social and sociological phenomenon (Freidson 2001). Let us consider each of the points in Wueste's composite summary of the defining features of professions: 
1. the centrality of abstract, generalized, and systematic knowledge in the performance of occupational tasks;

2. the social significance of the tasks performed by professionals; professional activity promotes basic social values;

3. the claim to be better situated/qualified than others to pronounce and act on certain matters;

4. the claim that professional practice is governed by role-specific norms - a professional ethic; and that,

5. most professionals work in bureaucratic organizations/institutions (Wueste 1994, 2013, 3).

Certainly, the production of abstract, generalized, and systematic knowledge is central to research. Indeed, in his comparison of academic sociologists and those who engage in what he presents as related occupational practices (such as journalist, novelists, and dramatists), Strong distinguishes between analysts and practitioners suggesting this is relevant to the fact that the former "have relatively weak professional organizations" (Strong 1983, 63). It seems, then, that those who make use of knowledge - which is to say practitioners - tend to be members of professional organizations, while the same cannot be said for those who produce knowledge, the defining task of research as an occupation or practice. Nevertheless, one might note that having and using one's knowledge is central to conducting research; it is central to the production and reproduction of further knowledge. For example, consider the methodology of a discipline or field. This can clearly be considered as a form of abstract, generalized, and systematic knowledge as well as something that is used or put into practice in the course of conducting research. One might, of course, take a pluralist approach to the methodology of a particular area of enquiry. Psychology, for example, can be pursued in a positivist or non-positivist manner, and it can be both a quantitative and a qualitative endeavor. More broadly, one can note that there may be tensions and disagreements about matters of methodology as well as substantive findings within any one field. Nevertheless, this does not undermine the fact that abstract, generalized, and systematic knowledge is central to the proper performance of research, it is merely to note that attending to and revising such knowledge is, to greater or lesser degrees, an ongoing task of disciplined research.

It also seems relatively noncontroversial to think that research has social significance and promotes basic social values. Were this not the case, it would certainly be difficult to imagine that society would fund research and researchers to the extent that is the case. Whether scholars of the humanities and social or natural sciences, the vast majority of researchers would see themselves as working toward the betterment of society. This can be understood in terms of their substantive research but can also be applied to the teaching activities the majority of researchers undertake as part of their broader role. This point is related to Wueste's next defining feature. Researchers often claim to be better suited and qualified to pronounce on particular issues or matters that are related to their field of expertise. Certainly, they undergo extensive programs of education 
and, in many fields, periods of (quasi)apprenticeship to other researchers. Indeed, researchers are often called upon to provide expert testimony in political and policy-making fora as well as in public debates. They do not, of course, act in the same way as other professionals, but insofar as they are better situated and qualified to undertake certain actions, including conceiving of and pursuing specific research projects, reviewing the manuscripts of other researchers, examining doctoral theses, external examining and validating degree programs at other institutions, playing a role on grant boards, and so forth; then they occupy a privileged position.

To some degree the fourth of Wueste's defining features of a profession is what is at stake in this chapter. There are, of course, broader role-specific norms involved in the practice of research, the norms of knowledge production, methodology, and writing style, for example. Nevertheless, both our concern and the notion expressed in this criterion are whether or not the practice of research is governed by a set of role-specific norms and whether there is or can be a professional ethics for research, the questions presently under discussion. The final point is, however, more easily affirmed. It seems clear that researchers tend to work within bureaucratic organizations or institutions. If nothing else, universities are examples of this phenomenon. However, more than this, the task of being a researcher involves one in broader bureaucracies - those associated with distributing research funding, for example.

There is, then, no obvious reason for thinking research should not be considered a profession or, at least, not to reject the idea outright, and at least on the basis of Wueste's conclusions, drawn from the sociological literature. Nevertheless, it is clearly the case that researchers do not belong to a formally institutionalized profession and are not recognized as such. Furthermore, research is constituted by a great deal of theoretical and methodological diversity, such that one might question if a unitary profession can, or ought to be, identified. Even if one were to advocate for the institutionalization of research and researchers as a profession, it would seem that the best one could hope for was the creation of a set of more or less affiliated (multi-)disciplinary groups, perhaps based on the existing model provided by the learned societies. Pursuing such a project is, however, unlikely to bear significant fruit. Fortunately, it is not necessary to promote the formalization of research and researchers within a profession in order to think through the possibilities for a professional ethics of research. Whether as a set of general propositions or, as in the case of the following chapters in this section (V - Disciplines and Professions), in more specific terms, what is important is the normative basis on which such an ethics can be understood and articulated.

\section{What Basis for a Professional Ethics of Research?}

In their essay, Revisiting the Concept of a Profession, Tapper and Millett note that "a profession involves: an ideal of service and responsibility to the public good; virtue on the part of professionals; and a special sort of fiduciary obligation." 
$(2015,4)$ While it is commonplace to present the moral obligations of professionals in terms of their special responsibilities toward their clients, the social license of a profession is something broader and entails a collective articulation and recognition of the goods offered by a profession. Thus, one can think of health as the broad public good promoted by the healthcare professions and promoting the rule of law - which is to say the fundamental basis on which contemporary society is rendered possible - as the public utility served by legal professionals. In this context one might consider what, if anything, is promoted by research and researchers. The short answer is, of course, knowledge, and while one should be reluctant to constrain the pursuit of knowledge by reference to the public good, one might also note that it is not possible to place a prior constraint on the pursuit of knowledge, given that one does not already know what one is endeavoring to find out. Of course, one cannot know in advance if or how a research project will serve the public good or not, at least not with certainty or precision. Indeed, the utility of research may not even be immediately apparent at the conclusion of the project; appreciating the value of knowledge and its creation requires the adoption of a longer-term perspective.

Consistent with the diversity identified above, we might acknowledge that the pursuit of knowledge in different domains offers significantly different goods. Broadly speaking, one might distinguish between the natural and the social sciences and the humanities. Each offers its own distinctive form(s) of insight into the world and ourselves. Equally, we might also think that knowledge is worth pursuing for its own sake, that it is its own good. (While he speculates about the end of knowledge in our global or globalized era, Delanty (1998) avers knowledge as the end of the university in the context of the enlightenment. Fuller (2003) also speaks of the university as a social technology for the production of universal knowledge.) Furthermore, one might think that the public good served by researchers is not simply the pursuit of new knowledge. Rather, as scholars and academics, researchers are the custodians of knowledge, something that maps onto ancient and medieval conceptions of the university, conceived as an autonomous institution (Minogue 1973). In this role researchers - academics - have pedagogic responsibilities, something that we might not only interpret in relation to a universities formally registered students, but as a broader social responsibility to profess one's knowledge in public. Of course the term professor and the idea of professing one's knowledge are not unrelated to that notion of a profession or professionals, which is to say, those who use their knowledge in service of their clients.

In this view, then, researchers are positioned as being in service to and having a responsibility toward knowledge, understood as a public good. In this context the fiduciary obligations of researchers relate to the knowledge they hold in trust and the sociopolitical role it plays. Consider, for example, the role of scientific knowledge in contemporary society. As Collins (2010) points out, we should not make the mistake of thinking political debates can be fully determined by scientific knowledge. Nevertheless, scientific testimony - or knowledge, knowledge claims, and knowledge production more generally - is not something that should be politicized (Collins et al. 2010). With regard to bioethics, this is 
something discussed elsewhere (Emmerich 2018a). In this context, however, one can understand the fiduciary responsibilities of researchers as, first, ensuring this does not happen in their own work and, second, offering counter testimony if and when they perceive it happening in broader public debates. While these fiduciary responsibilities can be reflectively, consciously, or conscientiously pursued, they are nevertheless a matter of virtue: the disposition or habitus of researchers. (One could, at the mention of virtue, present an account of the professional ethics of researchers in neo-Aristotelian terms. Certainly, MacIntyre (1981) provides the resource for such a task. However, I am disinclined toward such a project, which strikes me as overly ideal and requiring a top-down imposition of both virtue and the nature or what it is to correctly pursue (scientific) research. As a result one might prefer to think in terms of the (imperfect) dispositions (or habitus) of researchers, the social structures of a field (or discipline) and notions of immanent (self) critique. For a related discussion regarding the term phrónēsis and the use of this term in contemporary research ethics, see Emmerich (2018b).)

As revealed by historians of science (Shapin 2008; Daston and Galison 2007), the scientist (and, by extension, the researcher) is constituted by a particular set of dispositions, a habitus that encapsulates an epistemological ethos (Emmerich 2016a). This is, of course, something that is variable both historically and across the social space of intellectual fields or disciplines. The habitus of a scientist and that of an English literature scholar will differ significantly, while those located in other intellectual fields may be more closely aligned, as in the case of a (natural) scientist and an (analytic) philosopher of (the natural) science(s), say. We might also find significant differences within fields that, on the face of it, are more closely related, such as qualitative and quantitative social scientists, for example. While such differences are significant when it comes to the specifics of ethical practice in particular disciplines and domains and therefore present a challenge to the notion of a professional ethics of research as a singular or unitary phenomenon, they need not be taken as ruling out the idea entirely. Rather, consistent with any properly conceived ethics of research, it is simply the case that a professional ethics of research must be understood in pluralist terms. At least in part, this is because the normative dimension of research does not just concern the kinds of issues normally discussed under the rubric of research ethics, but are fundamentally linked to the practice or practices of research. These include specific issues, such as publication ethics, and broader notions such as research integrity.

This is an important point because, as MacIntyre (1981) has it, there is a strong connection between a profession and its practices. This is because of the way that the (internal) goods of a profession are instantiated and pursued through its constitutive set of practices. However, as Millett (2016) notes, the notion of practice is insufficient if we are to fully conceptualize the notion of a profession. As discussed above, there needs to be some form of institution that is central to the social existence and organization of the profession and its practices. Millett (2016) also argues that a profession and its host society enter into a social contract, one that enables the goods offered by a profession to be pursued by circumscribing the way(s) in which they can be pursued and by whom. The aforementioned 
notion that the university holds knowledge in trust and does so on behalf of society might be taken as something that reflects this notion of a social contract. It might also be perceived in the notion, common to American universities in the eighteenth and nineteenth centuries, that a large part of a university's purpose was the moral education of its students: the development of character (Reuben 1996, 75).

However, while Dewey (and others) continued to argue that universities should see themselves as vehicles for moral education well into the twentieth century, and while echoes of this can be perceived in the contemporary notion that attending university should entail undergoing some form of education for (global) citizenship, the notion is not central to the concept of research university. Wellmon $(2015,5)$, for example, traces the advent of the research university to early nineteenth-century Germany, with distinctive features of this institutional approach to the organization of enlightenment subsequently being reiterated elsewhere, notable late nineteenth-century America. Furthermore, according to Reuben (1996), the making of the modern university involved a marginalization of morality. Nevertheless Wellmon also notes that, as something that was organized around the institutionalization of a particular division of intellectual labor, namely, disciplinarity, the advent of the research university entailed both a process of specialization and one of professionalization (Wellmon 2015, 148-49 \& 233).

While it is arguably the case that a major imperative in the organization and structure of contemporary research activities, particularly within universities, seeks to go beyond disciplinarity and toward greater interdisciplinarity (Riesch et al. 2018), it seems unarguable that the professionalization of research and researchers is an ongoing project. Of course, the nature of this professionalization is inimical to the image of the lone scholar and, insofar as this is the case, to the autonomous, individual, and self-directed professional. However, as the sociological criteria for professions demonstrate, relying on an overly individualist account of the professional would be misguided. Professionals are not simply individuals, but representative of social organizations, members of institutions to which they are accountable.

Similar points can be made with regard to researchers. Consider, for example, processes of peer review for the purposes of publication, the allocation of grant monies and evaluation exercises. The social organization of disciplines or fields of enquiry means research is a team or community effort. Furthermore, while it may not (always) rely on peer review, the practice of research (ethics) governance and its development over the past few decades within universities around the world could be taken as further exemplifying this point. Certainly, the ethical accountability it seeks to engender is a social and collective endeavor. Furthermore, the way researchers are considered to be ethical actors and held responsible for their activities could be seen as reflecting the way in which other professionals are understood to be responsible for their activities and subject to codes of ethics. However, the ethical governance of research is, in many cases, not undertaken by a researcher's direct peers, but by researchers with a broader range of disciplinary profiles as well as others, including individuals who do not conduct research. Although nonprofessionals and laypersons are, today, included 
in the governance structures of formal professions, professional organizations nevertheless exercise a high degree of autonomy over the way they are governed and, in particular, the setting of ethical standards to which they are accountable. This is not the case for researchers. Indeed the notion that researchers should have primacy when it comes to setting the ethical standards of their field is inimical to the way research ethics is presently conceptualized and understood. Nevertheless if there is indeed a sense in which researchers can be understood as professionals, then exploring the ethics of research as a form of professional ethics may have merit and go some way to combatting the problems generated by research ethics in its current guise.

\section{Rethinking Research Ethics as a Professional Ethics}

As the foregoing analysis makes clear the social organization and institutionalization of research is such that it cannot be thought of as a (formal) profession or set of professions. Nevertheless, we have also seen that there is some reason to think that research is a professional activity in the relevant sense. Equally, it is also clear that both the discourse that surrounds and constitutes the ethics of research and its implementation or administration differs from that of professional ethics. The question is, then, whether thinking of researchers as professionals can make a positive contribution to the way we think about the both the ethics of research and the way in which we approach its governance.

Perhaps the first thing to note is that current developments in research ethics specifically, concern for the integrity of research and, therefore, the character of researchers - is a mode of thought that is clearly more consistent with the kind of thinking found in accounts of professional ethics than with the prior discourse on research ethics. At its inception, part of the purpose of research ethics was to move beyond the domain of professional ethics so as to prevent inter-professional conflict (Stark 2011). What was accomplished was the elimination of the specific individual or professional in the discourse of research ethics, replacing them with a uniform or generic image of the researcher, as an everyman.

Of course this coheres with the way the researcher is conceptualized, particularly within the natural sciences. Scientists are understood to be objective, impartial, and neutral observers, whose standpoint is idealized as the view from nowhere. It follows that the "common sense" vision of good science entails the elimination of the researcher at all stages of its conduct. While similar thoughts can be applied to professionals - what it is to be a professional is to suspend one's private self and take on a particular social role that entails a certain level of neutrality or impartiality, even as one acts in the interests of one's client or patient - this is taken further in the context of the scientist and the researcher, at least as conceptualized within dominant discourses on research ethics. The ideas pursued in this chapter aim at refitting the notion of the researcher as a professional. As such, they are consistent with intellectual developments in our understanding of science since the publication of Kuhn's (1996) Structure of Scientific Revolutions, 
particularly more recent work in the history and sociology of science, that recognizes the importance of the social role and the professional or intellectual character scientists and researchers inhabit, and its relationship to the production of (scientific) knowledge.

In the context of such post-Kuhnian perspectives, the notion of integrity can be taken as both an ethical and epistemological initiative. As Daston and Gallison suggest, the advent of scientific modes of thought entailed that an "[e] thos was explicitly wedded to epistemology in the quest for truth or objectivity or accuracy" (Daston and Galison 2007, 204). Such an ethos is reflected in the way science is done; it is a regulative, which is to say normative, set of values or ideal(s) that guides and informs scientific practices. At least in part, its operation entails shaping the character of scientists and, relative to their own disciplinary and intellectual fields, researchers more generally. Thus, Daston and Galison go on to say that "[f]ar from eliminating the self in the pursuit of scientific knowledge, each of the epistemic virtues depended on the cultivation of certain character traits at the expense of others ... [resulting in an] ethical and epistemological code imagined as self" (Daston and Galison 2007, 204). As previously pointed out an ethos, and the character of a researcher, is mutable, it varies across time, place, and discipline. It is something that can be extended and generalized, as has been suggested in relation to bioethics (Emmerich 2018a). Thus the emergence of integrity as a regulative ideal in the discourse on research ethics can be seen in terms of changes and developments within both particularly disciplines and within research and its associated institutions particularly universities - more generally.

A disciplinary ethics can, then, be seen as wedded to its epistemology, something that is reinforced by the rubric of integrity. As a result the concept of integrity is something that should be understood as requiring further iteration in specific disciplinary contexts. The notion of integrity is consistent with and furthers the notion that the discourse of research ethics should be - and, perhaps, is being - reformulated as a professional ethics. In this context the views of professionals, i.e., those who inhabit the ethos and character of a particular discipline, take on greater significance than mainstream research ethics would suggest, particularly in the context of the governance and review of research. This should not, however, be mistaken as an argument for simply prioritizing the substantive ethical perspectives of researchers or for insulating their views from criticism. Rather this present account, and those which emphasize the importance of integrity to ethical research, suggests that researchers should actively engage with the ethical dimension of conducting research within their field(s) and, as part of this, engage with those who have a stake in the debate. This should, of course, include research participants or those who can be taken as representing their views or interests. It should also include external commentators (notable bioethicists or research ethicists). It might also include a range of other stakeholders including funders, gatekeepers and those working within research administration and governance. It might also include the public in a more general sense, depending on the nature of the research at hand. 
Furthermore, when considering the ethics of their research, researchers should remain conscious of the (implicit) social contract that exists between their discipline and the society they inhabit. This is, of course, not a simple relationship, and it well be subject to a significant degree of variation. Consider the notion in relation to, say, the biomedical sciences and English literature. Given the respective purposes of these fields, and the potential risks attached to each, researchers have differential responsibilities when it comes to demonstrating that they are acting in the best interests of society as a whole. Equally, consider the social sciences, particularly in its more critical instantiations. Here, what is proper to both research and the researcher may well entail a certain degree of antagonism when it comes to the interests of particular groups or society as a whole. The social responsibilities of social scientists may include telling people what they do not want to hear: to "speak truth to power" to use a rather grandiloquent phrase. Arguable it is here that the social contract takes on primary importance. Social scientists do not offer criticism for criticisms sake but do so with regard to longer-term interests.

From one point of view, this could be taken as being tantamount to a rejection of the idea that researchers engage in the pursuit of knowledge for its own sake or that knowledge is its own end and justification. However, one might also take this as the basis or motivating factor on which a social contract between a society and the academics and researchers it hosts and supports is formed. If something is valued for its own sake, then it is valued by all and not by those engaged in its pursuit alone. Further justification or motivations for investing in the pursuit of knowledge offer reasons which might shape the way research, and researchers are sociologically and politically institutionalized. Consider, for example, the Manhattan Project and the specifics surrounding the institutionalization of nuclear research and physicists at Los Alamos in the USA during World War II or endeavors such as The Human Genome Project. While knowledge for its own sake might provide a broad context in which to understand the relationship between researchers and society, it also seems clear that a more detailed view of both national and international politics as well as the scope of current research can result in more complex forms of arrangement and organization. In this context it would seem clear that a commitment to knowledge and the value of research on the part of both researchers and their institutions, particularly universities, and society, particularly in the form of governments, nevertheless leaves a great deal of scope within which the pursuit of such knowledge can be organized and structured.

Arguably, the ethics of a profession is rooted in such broad sociopolitical arrangements and such arrangements are, of course, themselves open to ethical reflection or ethico-political debate. Nevertheless they offer a possible foundation for a professional ethics of research. It is, to be certain, a potentially shifting ground and one that offers far less clarity than, say, the four principles approach developed by Beauchamp and Childress (2009). (One should recall at this point 
that the four principles of biomedical ethics were initially developed in the context of the Belmont Report, something that was primarily concerned with biomedical research and the historical source for current research ethics regulation in the USA (Schrag 2010). That they later became highly influential in the context of medical practice and healthcare as well as biomedical research augurs well for any refusal to disconnect research ethics from professional ethics, as argued in this chapter.) Nevertheless, it is one that can accommodate the kind of thinking the four principles presents, which has been influential in discussions of both research ethics and the ethics of the healthcare professions. Thinking of research ethics as a professional ethics does not mean repudiating what has gone before. Rather it means casting researchers in a different light as well as thinking about the ethics of research in broader terms.

\section{Conclusion}

This chapter has suggested that it may be fruitful to rethinking research ethics as a form of professional ethics and to think of researchers as professionals. While there is some prima facie reason to reject such ideas - not least the absence of any formal professional institution(s) and the fact that advocating for their development from the current panoply of associations is unlikely to meet with success - there is value in considering the notion in more detail. This is particularly true when one considers some of the current developments in research ethics, particularly the turn toward integrity. In this context the notion of a professional ethics of research and researchers has much to offer. In particular it suggests the ethics of research can be connected to the professional character of the scientist or to the discipline of researchers. In light of the analyses presented by those who study the practice of science, this perspective creates an opportunity to forge a closer connection between ethics and epistemology and, therefore, between ethics and methodology. It also promotes consideration of the broader sociopolitical contexts in which research actually takes place and in which professional researchers are situated. Indeed, it presents an opportunity to both embed ethical discourses within particular disciplines to promote broader discussion across disciplinary boundaries. If research ethics is a professional ethics, then research professionals ought to take clearer ownership of existing and emerging ethical issues that affect or arise within their particular fields, both in substantive terms and in terms of promoting broader engagement with others that can be considered as having a stake in the debate. This includes those who participate in research as well as those, such as funders, managers, and administrators, whose actions impact the way research is conducted in a broad sense. If we consider research ethics to be a professional ethics, then it is no longer just about specific research projects, but the enterprise as a whole. 


\section{References}

Beauchamp TL, Childress JF (2009) Principles of biomedical ethics, 6th edn. Oxford University Press, Oxford

Collins HM (2010) Elective modernism. Unpublished Manuscript. Unpublished. http://www.cardiff. ac.uk/socsi/contactsandpeople/harrycollins/expertise-project/elective $\% 20$ modernism $\% 204$.doc

Collins HM, Weinel M, Evans R (2010) The politics and policy of the third wave: new technologies and society. Crit Policy Stud 4(2):185-201. https://doi.org/10.1080/19460171.2010.490642

Daston L, Galison P (2007) Objectivity. Zone Books, New York

Delanty G (1998) The idea of the University in the Global era: from knowledge as an end to the end of knowledge? Soc Epistemol 12(1):3-25

Emmerich N (2016a) Ethos, Eidos, habitus: a social theoretical contribution to morality and ethics. In: Brand C (ed) Dual process theories in moral psychology. Springer, Dordrecht, pp 275-300. http://link.springer.com/chapter/10.1007/978-3-658-12053-5_13

Emmerich N (2016b) Reframing research ethics: towards a professional ethics for the social sciences. Sociol Res Online 21(4):7

Emmerich N (2018a) Elective modernism and the politics of (bio)ethical expertise. In: Riesch H, Emmerich N, Wainwright S (eds) Philosophies and sociologies of bioethics. Springer, Dordrech, pp 23-40. https://doi.org/10.1007/978-3-319-92738-1_2

Emmerich N (2018b) Chapter 11: From Phrónesis to Habitus: Synderesis and the practice(s) of ethics and social research. In: Virtue ethics in the conduct and governance of social science research. Advances in research ethics and integrity, vol 3. Emerald Group Publishing, Bingley, pp 197-217. https://doi.org/10.1108/S2398-601820180000003012

Evetts J (2003) The sociological analysis of professionalism: occupational change in the modern world. Int Sociol 18(2):395-415. https://doi.org/10.1177/0268580903018002005

Evetts J (2013) Professionalism: value and ideology. Curr Sociol 61(5-6):778-796

Freidson E (2001) Professionalism, the third logic: on the practice of knowledge. University of Chicago Press, Chicago

Fuller S (2003) The university: a social technology for producing universal knowledge. Technol Soc 25(2):217-234. https://doi.org/10.1016/S0160-791X(03)00023-X

Hedgecoe A (2016) Reputational risk, academic freedom and research ethics review. Sociology 50(3):486-501. https://doi.org/10.1177/0038038515590756

Kuhn TS (1996) The structure of scientific revolutions, 3rd edn. University of Chicago Press, Chicago

MacIntyre A (1981) After virtue: a study in moral theory. Duckworth, London

Tapper A, Millett S (2015) Revisiting the concept of a profession. In: Conscience, leadership and the problem of 'dirty hands'. Emerald Group Publishing, pp 1-18

Millett S (2016) How should the concept of a profession be understood, and is the notion of a practice helpful in understanding it? In: Contemporary issues in applied and professional ethics, vol 15. Emerald Group Publishing Limited, Bingley, pp 29-40. https://doi.org/10.1108/ S1529-209620160000015002

Minogue KR (1973) The concept of a university. New Brunswick, USA. Transaction Publishers

Reuben JA (1996) The making of the modern university: intellectual transformation and the marginalization of morality. University of Chicago Press, Chicago

Riesch H, Emmerich N, Wainwright S (2018) Introduction: crossing the divides. In: Riesch H, Emmerich N, Wainwright S (eds) Philosophies and sociologies of bioethics. Springer, Dordrecht, pp 1-22. https://doi.org/10.1007/978-3-319-92738-1_1

Schrag ZM (2010) Ethical imperialism: institutional review boards and the social sciences, 1965-2009. The Johns Hopkins University Press, Baltimore

Schrag ZM (2014) What is this thing called research? In: Glenn Cohen I, Fernandez Lynch H (eds) Human subjects research regulation: perspectives on the future. Cambridge, Mass. MIT Press. p 285

Shapin S (2008) The scientific life: a moral history of a late modern vocation. University of Chicago Press, Chicago 
Stark L (2011) Behind closed doors: IRBs and the making of ethical research. University of Chicago Press, Chicago

Strong PM (1983) The rivals: an essay on the sociological trades. In: Dingwall R, Lewis P (eds) The sociology of the professions. Macmillan, London

Wellmon C (2015) Organizing enlightenment: information overload and the invention of the modern research university. Johns Hopkins University Press, Baltimore

Wueste DE (1994) Introduction. In: Professional ethics and social responsibility. Rowman and Littlefield, Lanham

Wueste DE (2013) Trust me, I'm a professional: exploring the conditions and implications of trust for the professions. In: Ethics, values and civil society. Emerald Group Publishing, pp 1-12 